\title{
Resources and Threats of the Eco-Tourism Development in Georgia
}

\author{
Giorgi Khomeriki ${ }^{1}$, Giorgi Meladze ${ }^{2}$ \\ ${ }^{1}$ Vakhushti Bagrationi Institute of Geography at Iv.Javakhishvili Tbilisi State University, Tbilisi, Georgia \\ ${ }^{2}$ Dep. of Geography, Iv. Javakhishvili Tbilisi State University, Tbilisi, Georgia
}

Email address:

gogihom@hotmail.com (G. Khomeriki),meladzeg@gmail.com (G. Meladze)

\section{To cite this article:}

Giorgi Khomeriki, Giorgi Meladze. Resources and Threats of the Eco-Tourism Development in Georgia. American Journal of Environmental Protection. Special Issue: Applied Ecology: Problems, Innovations. Vol. 4, No. 3-1, 2015, pp. 180-185. doi: 10.11648/j.ajep.s.2015040301.38

\begin{abstract}
Ecological tourism can play a certain role in solving the problems of environment protection and sustainable and safe development of the country. The article considers some specific problems of the eco-tourism development in Georgia. The results of the study of the tourism potential in the regions in 2009-2014 revealed that: Georgia has substantial means to develop eco-tourism. This is true not only for the protected areas, but also for individual natural and geographical areas of the different regions (historical areas) of the country. The distinctive feature of the country's eco-tourism potential is particularly diversified relief forms and natural eco-systems, in particular, intense variation of the landscapes and great contrasts between them (seaside and mountain, humid subtropical and arid zone, river gorges and steppe landscapes alternate over small areas), widely distributed endemic biological species, and traditional ethnographic, farming and domestic cultural forms survived in the historical regions (mostly in the mountains) of the country. The principal eco-tourism value is the natural eco-systems being only insignificantly modified due to industrial changes and maintaining their "natural originality". In addition, numerous remnants of historical and cultural heritage give them a certain value. They naturally merge with the environment and not dominate over it, but add to its beauty. The threats to the environment are mostly associated with an increasing anthropogenic "aggression", destruction of the traditional mode of nature management meaning certain degree of responsibility and deficient environmental laws and mechanisms of their execution. The problem is further aggravated by the fact that due to the limited territories, the eco-systems of the country are particularly sensitive to technogenic pressure. Concrete eco-tourism projects must inevitably envisage preliminary geo-ecological works.
\end{abstract}

Keywords: Eco-Tourism, Resources, Threats, Visitors, Georgia

\section{Introduction}

In recent years, ecological tourism has been actively developing in Georgia, which is important for the perspectives of the rational use of resources and positioning of the country on the world tourism market. The article considers some specific problems of the ecotourism development in Georgia.

Tourism in Georgia started to develop in the XIX century and was associated with the curative and health-improving properties of the natural environment and aesthetic values of the country. However, it should be said that in the past, tourism with its incomes greatly was behind other branches of economy.

The economy of modern Georgia is still in its transformation phase, and the objective of Georgian economics is to identify and concentrate on the sectors of economy capable of making the country competitive. In solving this problem, the trends of the international markets and the country's own resources should be considered. In this respect, the ecotourism potential of Georgia's natural environment becomes increasingly important. Fortunately, unlike many developed industries, there are undisturbed ecological systems, natural landscapes and natural sights survived in Georgia being an object of increasing interest on the international tourist market. In Georgia there are fourteen types of landscapes and seventy one genera [1]. According to the landscape diversity, Georgia is in $12^{\text {th }}$ place in the world. But with regards to the amount of landscape types per square $\mathrm{km}$, Georgia is in the first place. In other areas that are the equal in size to Georgia we may find only one type of landscape, while in Georgia we have twenty two, so ten times more than in other regions [2]. In spite of the fact that 
Georgia possesses a small territory (69.7 thousand sq. km), it has approximately all the landscape types represented in the world, except savannas, deserts and rainforests. In Georgia we have approximately all types of landscape zones, which range from humid, dry subtropical valleys to high mountain alpine and glacier zone [3]; There is the sharply expressed vertical zonation of landscapes. The country's highest peak is mount Shkhara (5203 m), while the lowest point is located between Poti and village Kulevi (1.2-2.3 m below sea level) [4].

On the background of the aggravated natural threats worldwide, we can assume that these assets of our natural environment will be more valuable, while their protection is going to be a more urgent issue in the future. We agree that the most important resources serving as a support for the competitive strategy of Georgia are natural conditions and natural resources of the country, including eco-tourism potential. In this respect, the promotion of ecotourism development seems one of the most important directions of the sustainable development of the country.

It is known that in the historical past, Georgia had natural areas and objects protected by the state or society. For instance, as far back as in the XII century, Queen Tamar of Georgia issued a royal decree to protect certain territories of the country, and in the seventeenth century, the Code of Laws issued by King Vakhtang VI of Georgia established the territory of Korughi as a protected object, where cutting trees, farming and even walking was prohibited, and this territory was protected by guards [5]. It is also known that there were so called Khati (place of worship) forests in the mountainous regions of Georgia in the past, which were protected by the local communities. Virtually, these forests were reserves. In 1912, Lagodekhi Reserve was established in Kakheti. It was the first official reserve in Georgia. In the following years of the XX century, there were other reserves, managed reserves and protected areas established in Georgia.

Adoption of the Law Concerning the System of Protected Territories by the Parliament of Georgia in 1996, lying the foundation to the establishment of the environmental protection standards and categories based on the recommendations of International Union for Conservation of Nature (IUCN) [6] in Georgia was an important fact. From this time onward, a system of territories protected by the state with a single management started to develop, with the promotion of ecological tourism as one of its priorities.

\section{Study Area \& Methods}

The study covers the protected areas of Georgia, with the following National Parks being the principal eco-tourist destinations: Algeti, Borjomi-Kharagauli, Vashlovani, Tbilisi, Tusheti, Kolkheti, Machakhela, Mtirala, Kazbegi and Javakheti. The eco-tours are partially admitted to other areas, such as Tusheti and Kintrishi protected landscapes as well as managed reserves, where in addition to eco-tours, other tourist activities are also admitted.

The total area of the National Parks of Georgia is 2767 sq. $\mathrm{km}$, making almost $4 \%$ of the territory of the country. The National Parks are established in different corners of Georgia. The objects they protect (endemic biological varieties, unique landscapes, undisturbed ecological systems and historical-cultural monuments) are vary significantly in nature. On the one hand, the National Parks include the eco-systems typical to wet subtropics, e.g. the eco-systems in Mtirala or Kolkheti National Parks, and on the other hand, they cover the eco-systems typical to arid landscapes, e.g. the ones found in Vashlovani National Park. Borjomi-Kharagauli National Park is distinguished for a unique eco-system of coniferous forests, while Tusheti National Park is known for a rare variety of endemic biological species (the National Park includes 230 Caucasian endemic species, with 11 of them found only in Georgia), and accommodation, historical and ethnographic values of the local settlements. All other National Parks also have distinctive features.

The study is based on the expeditions organized in the protected areas and perspective eco-tourist areas (Kvemo Kartli, Erusheti Ridge, Guria mountainous area, Javakheti volcanic mountainous area, etc.) in different years. In addition to the direct observations, the study uses literary, statistical and cartographic methods. The article presents the primary results of the study of the ecological tourism development in Georgia. The next stage will be dedicated to the geo-ecological and tourist-geographical study of the individual protected areas.

\section{Results \& Discussions}

Ecotourism is a relatively new branch in Georgia. Its origination and development are associated with the protected areas.

At present, there are 10 national parks, 14 state reserves, 18 managed reserves and 2 protected landscapes in Georgia, with different kinds and degrees of tourist activities permitted.

Tourism in the protected areas of Georgia is characterized by an increasing trend (fig. 1). According to data of the Agency of Protected Areas, the number of ecotours and visitors in the protected areas over the recent years has been featuring a dynamic increase. In particular, the total number of visitors increased from 12,2 thousand to 417,8 thousand more than 34-fold increase - over the period of 2008-2014. The greatest boost in the number of visitors was featured in 2011 (with 240\% growth). As for 2012, it was characterized by a slight fall of the same number. However, in the following years, the rate of increase in the number of visitors recovered.

The 2014 reduction (to $+1.9 \%$ ) of the increase rate of total annual number of tourists in Georgia was not reflected in ecotourism $(+19,2 \%)$. This could be explained by the fact that the main generating countries for ecotourism - Israel, Germany, Poland, Russia and Ukraine - were affected less by the stricter visa regulations imposed by the Georgian government in 2014 that made the visa procedures more complicated. The regulation changes were directed more at 
countries visitors from which represented insignificant part of the ecotourism field - namely Iran, Egypt, Iraq and China.

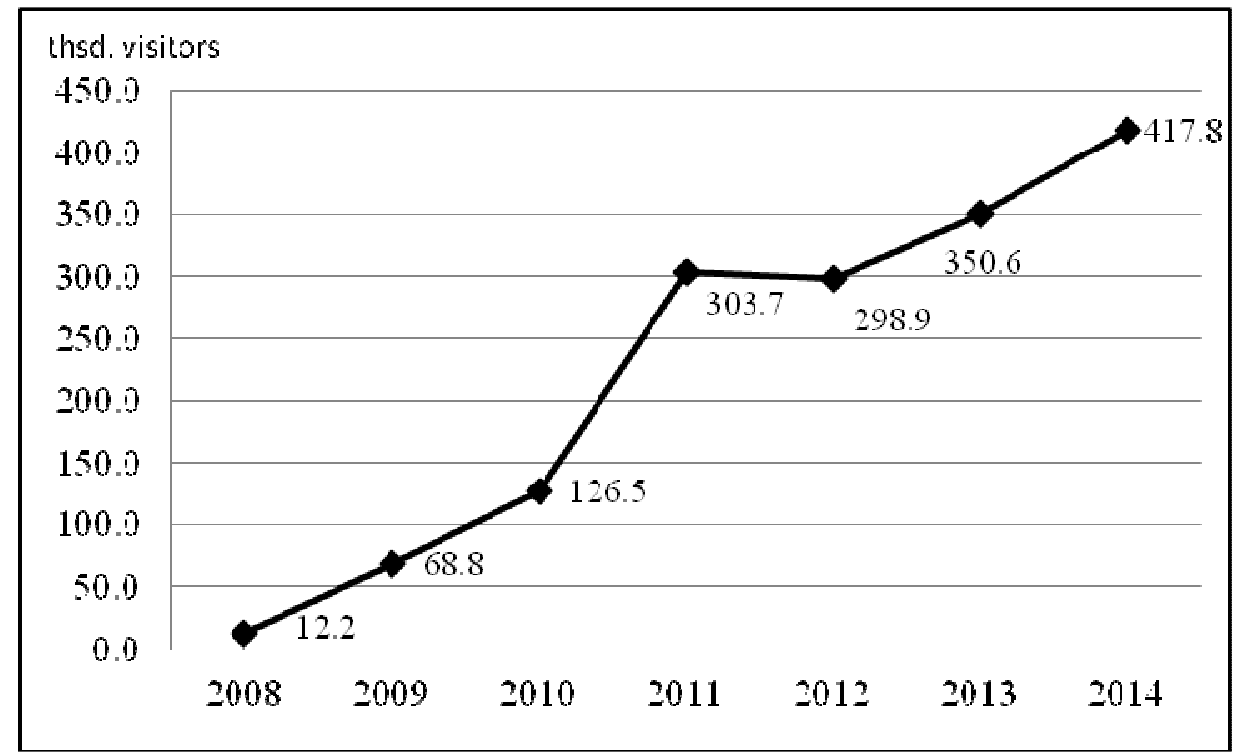

Figure 1. Total number of visitors to the protected areas of Georgia

Source: Georgian National Tourism Administration

Similar changes are reflected in income dynamics (fig. 2). Revenue from ecotours in protected areas over 2008-2014 increased 23-fold (55,7 thousand to 1318,1 thousand GEL). As the given figures show, the rate of income growth until 2011 (48\% of the average annual increase) significantly fell back the rate of growth of the number of visitors $(500 \%$ of average annual increase). However, from 2011, the rate of income growth tended to increase rapidly and overcame the rate of growth of the visitors' number. This can be explained by the establishment of new territories and improvement of the reception facilities and infrastructure for the eco-tourists in the protected areas in 2011.

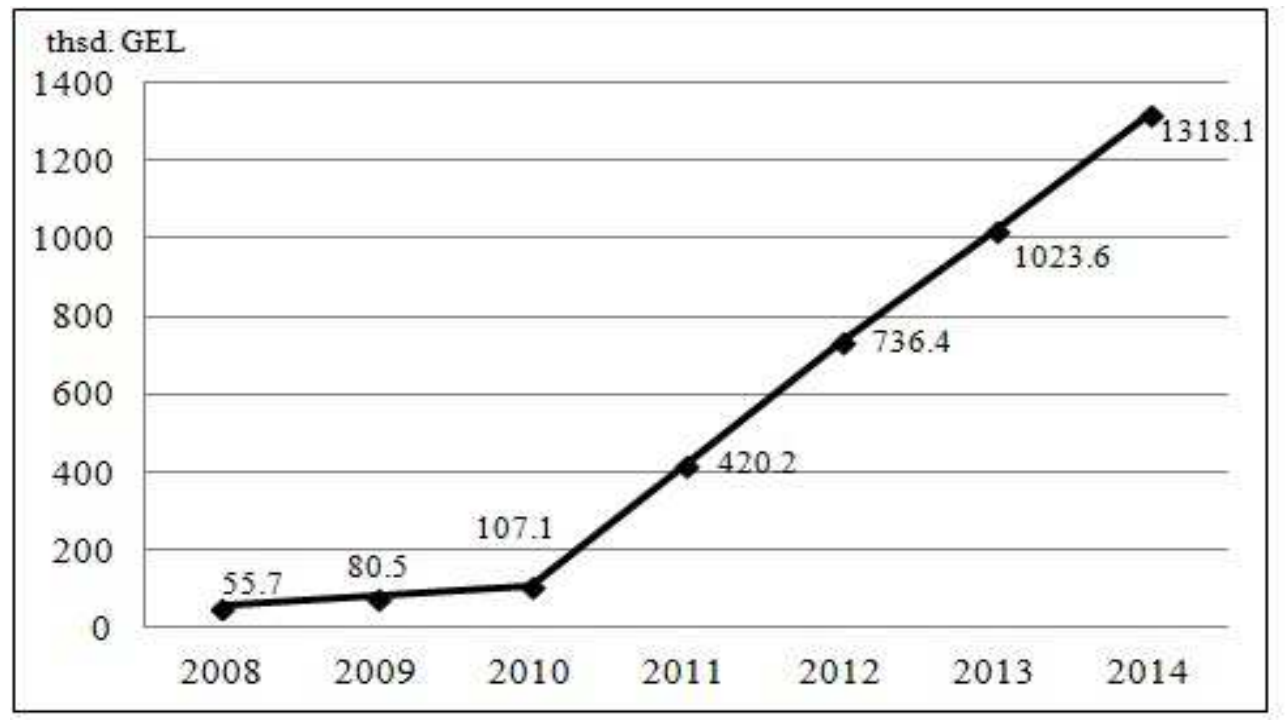

Figure 2. Size of Incomes from the Protected Areas of Georgia

Source: Agency of Protected Areas.

As per the structure of visitors to the protected areas, several countries worldwide are remarkable in this respect. In 2014, most tourists traveled from Israel (16,9 thousand people), followed by Russia (15,1 thousand people), Ukraine (13,6 thousand), Poland (13,1 thousand) and Germany (5,8 thousand).

The visitors are mostly young people up to 35 years of age, mostly traveling in groups of 4 to 6 . The distribution of visitors in different protected areas is very interesting (fig. 3). 


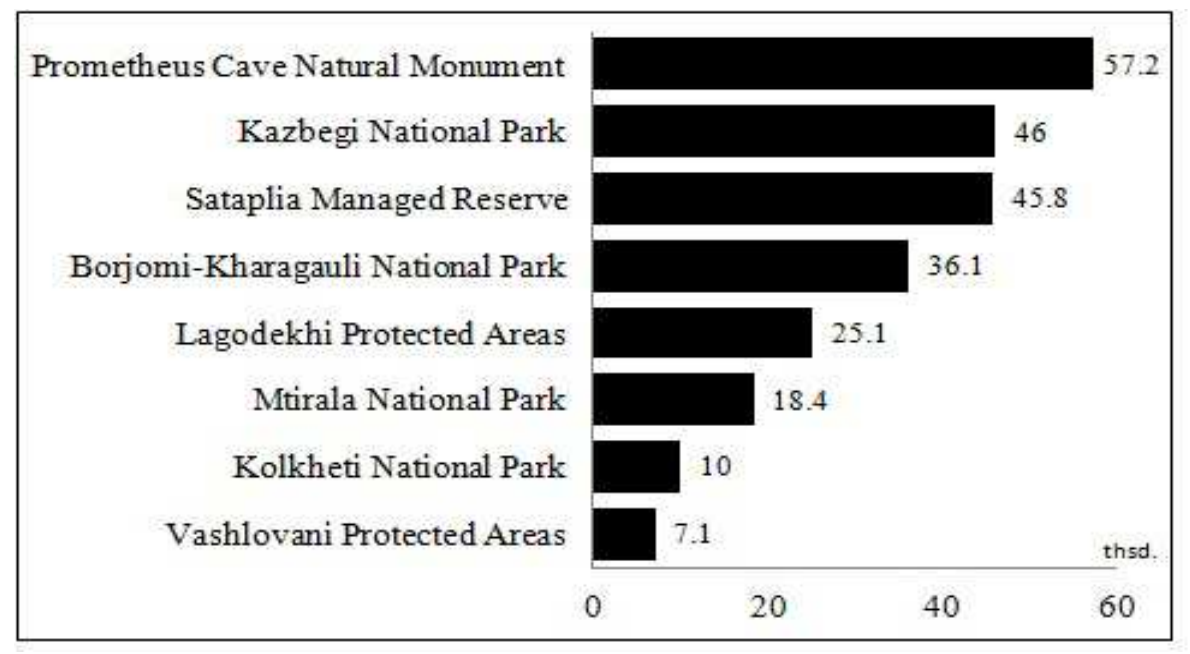

Figure 3. Distribution of Visitors by Protected Areas by 2014

Source: Agency of Protected Areas.

As the figure 3 shows, outstanding destinations are Prometheus and Sataplia karst caves. In our opinion, the major reason for this is the best equipment and facilities of these destinations and large and efficient private investments in them [7].

It should be noted that the system of tourist reception, accommodation and service still fails to meet the visitors' demands. The same is true with cognitive ecological programs [6]. Recovering these deficiencies is essentially important to attract eco-tourists and create the perspectives to increase incomes in the future.

The trend of increasing number of ecotourists in Georgia is first of all, caused by the increasing interest in Georgia on the world tourist market as in a country with fresh and important tourist and recreational resources. The number of tourists to the country is characterized by a general increase. As per the data of the Ministry of Internal Affairs of Georgia, the number of visitors to the country has steadfastly increased in recent years $(+23,4 \%$ per year). In 2014 the rate of increase in total (tourist as well as non-tourist) arrivals to Georgia was reduced to $+1,9 \%$ (The number of the total arrivals exceeded $5 \mathrm{mn} 493$ thousand) [8]. This reduction was mostly caused by external factors - mainly the unstable political and economic situation in Ukraine and Russia. Despite this the rate of increase in tourist visits was reduced to a far less degree - the number of tourists ( $2 \mathrm{mn} 218$ thousand) represented a reduction to $+7,4 \%$ increase rate compared to the previous year [8].

The country has all three components of the ecological tourism potential: nature diversity, variety of historical and cultural heritage and ethnographical diversity. However, there are problems, which are to be solved to develop the perspectives of ecotourism.

The number of tourists is expected to continue to grow in the future, and the stress on the natural eco-systems and traditional economic and ethnographic properties of local communities will increase consequently. Besides, as it is known, these major resources of ecotourism are very sensitive to excessive anthropogenic impact.
Therefore, when planning and organizing the eco-tours, the limits of the admissible number of tourists to the protected areas are to be taken into account by considering the specifics of each eco-system. This problem can be solved by accomplishing ecological, geo-ecological and touristic-geographical studies.

Developing the ecotourism in a qualitative rather than quantitative respect is particularly important. In particular, the guest reception facilities, such as accommodation, catering, recreation, entertainment and cognitive facilities and infrastructure must be provided in greater numbers and modernized to be an organic part of the surrounding environment and not surpass it; an increase of per tourist income should be promoted, and it is also important to prolong the touristic season.

Development of the local market of ecotourism is an important reserve. The specific weight of domestic travelers is still very little. The problem here is the high prices of service incompliant with the purchasing ability of the population [6].

In the experts' opinion, the major deficiency of tourism is the underdeveloped touristic business in Georgia in the peripheries of the country, as well as inflexible management, poor service, non-proficiency in foreign languages, outdated material-technical base and infrastructure, lack of modern standards and high service prices not corresponding to the service quality [6, p.7].

The major goal of establishing and developing a system of protected territories is the protection and maintenance of bio-ecological values of the natural environment, such as bio-diversity and endemic and rare biological species. As it is known, the Caucasus was named by the IUCN among 34 world hotspots, particularly rich in species and with great bio-diversity and was named by the World Wildlife Fund among 200 key eco-regions of the world [6. p.21].

Villages and communities of Georgia are also an important eco-tourist resource. Remote and often abandoned mountain villages, as well as villages with the survived elements of the traditional Georgian life and farming and ethnic villages 
survived at some places of the country (e.g. villages of German Lutherans, dukhobors, Daghestani or Greek people and other nationalities) are a subject of the keenest interest. As the incoming tour-operators state, such destinations are in great demand. On the other hand, due to a number of respects.

The threats to the nature of Georgia, the major riches of the country, is the aggravated ecological problem, such as reduced forest areas, active erosion processes, devastated bio-diversity, fertile soils occupied with industrial and construction sites, accelerated deforestation and active natural calamities, are to a great extent associated with the irrational and irresponsible nature management. The situation can be rescued through active environmental measures, with the expansion of the system of the protected territories as one of the major measures.

The nature of Georgia has significant resources to expand the eco-tourist areas. There are a number of undisturbed natural eco-systems survived in Georgia and there are areas with ecologically valuable objects of different scales. There are forms of organic unity of society and nature still found in our natural environment. The historical monuments and traditional villages scattered in the nature add to the attractiveness of the country. At this point, there is one conceptual issue of how to treat ecotourism. Is it cognition only, or is it also visiting the environment being in an organic co-existence with humans?

Another principal opinion concerns the role of the non-living nature in the selection of the protected areas. Surely, the rare species of living nature of Georgia need protection, but it does not seem fair to us to underestimate the role of non-living forms of the eco-systems, such as relief forms, soil, watercourses, karst landscapes or climatic conditions in the eco-systems. In fact, the geographical specifics of these elements of the eco-systems result in the diversity of the biological species. It is the non-living nature subject to a much more intense negative industrial and anthropogenic stress with consequent influence on the whole eco-systems. In our opinion, when creating the new protected areas in the future, the necessity for protecting the non-living nature should be considered. This opinion is based on the observations made during the complex geographical expeditions organized in the regions of Georgia in recent years.

During our expeditions, the primary study of the ecological complexes and rare relief forms revealed the objects, which can be formed as protected areas and consequently, become an active ecotourism objects. In our view, such objects can be:

- Individual cliffy systems of various hypsometric heights and originations, in particular mountain ridges, e.g. Birtvisi, etc.

- Large karst formations, e.g. karst massif of Racha, which is very large, but in fact remains unstudied [9].

- Mountainous zone in Guria: mountain forests, mouths and upper reaches of the Rivers Gubazeuli, Bzhuzhi and Supsa, Bakhmaro and Gomismiti Resorts, including the Reserve of Pontic oak. This zone is subject to heavy anthropogenic impact and the eco-systems here degrade rapidly.
- Gorges in Kvemo Kartli: the canyons of the Rivers Khrami (near Samshvilde), Chivchavi and Karabulakhi [10].

- Javakheti volcanic mountainous area with impressive megalith monuments formed (Shaori and Abuli fortresses, monastery cut in Samsari cliff) [11].

- Mountainous zone in Samegrelo: Egrisi Ridge, the River Khobistskali Gorge, Lake Tobavarchkhili.

- Erusheti Mountainous zone in Samtskhe.

- Davitgaredja, etc.

\section{Conclusions}

Ecotourism in Georgia is characterized by increased rates. The number of visitors and incomes grow rapidly. The major factor contributing to the growing interest in this kind of tourism and ecological activity is the important natural resources of the country, in particular, diversified landscapes densely clustered in different areas, surviving undisturbed eco-systems and endemic biological species mostly found in the protected areas.

Some of the negative factors are the underdeveloped specific material-technical and scientific-information bases for tourist reception and the inflexible pricing system.

The prospects for the ecotourism development are associated with the establishment of the new visitor service objects in the protected areas and perfection of the existing ones, as well as the extension and perfection of the research and cognitive programs.

Extension of the system of the protected areas with the ecologically valuable but threatened eco-systems and non-living nature objects, which are not a part of the system at present, represents a significant potencial.

With regards to state policy, it is important to ensure a well-organized development of ecotourism in the country based on the reasonable strategy, by strictly observing the ecological norms and considering scientifically developed recommendations.

\section{References}

[1] N.Beruchashvili. Landscape Map of Caucasus. Tbilisi, Scale $1: 1,000,000$.

[2] N.Beruchashvili.Diversity of Georgia's Landscapes and Geographical Analysis of Landscapes Diversity of the World. Proc. of the First National Conference: Biological and Landscape Diversity of Georgia. Tbilisi, 2000, 221-250

[3] Nikolaishvili D., Matchavariani L., Demetrashvili O. Methodology of Determining the Agri-tourism Potential on Georgia's Example. Journal of Tourism Challenges and Trends - Rural Tourism, vol. IV, No 1, 2011, 59-76

[4] Nikolaishvili D., Donadze T., Meladze G., Trapaidze V., Dvalashvili G., Sharashenidze M., Tigishvili T. Evaluating the Touristic Potential of Georgia's Landscapes. Forum geographic. Vol. XI. Issue 2 (12-12-20112), 2013, 145-154.

[5] Protected Areas of Georgia. Tsignis saxelosno, Tbilisi, 2007, 5. 
[6] Assessment of Ecotourism Potential in Georgia. IUCN, Tbilisi, 2008.http://www.greengeorgia.ge/sites/default/files/Ecotouris $\mathrm{m} \% 20$ Assessment $\% 20 \mathrm{in} \% 20$ Georgia.pdf

[7] G.Khomeriki, D.Maisuradze, K.Tsikarishvili, T.Khucishvili. Carst Caves of Georgia as the Significant Tourist Resource. Geography of Georgia, TSU, N 6, Tbilisi, 2007, pp. $69-78$.

[8] http://www.police.ge/ge/useful-information/statistics/sazghvri s- kvetis-statistika

[9] M. Gongadze, G. Lominadze, G. Khomeriki. Karst of the Racha Range and its Touristic and Recreational Potential. Collected papers of Institute of Geography of Georgia. New series, N 6 (85). Tbilisi, 2014. 53-57.

[10] G. Khomeriki, V. Neidze, M. Tutberidze, M. Gongadze, G.Lominadze, N.Chikhradze. Tourist-Recreational Potential of Kvemo Kartli (Geographical Analyses. Collected papers of Institute of Geography of Georgia. New series, \#N4 (83). Tbilisi, 2012, 237-246.

[11] V. Neidze, M. Tutberidze, G. Khomeriki. Tourism in Djavakheti: Development Factors. Collected papers of Institute of Geography of Georgia. New series, N5 (84). Tbilisi, 2013. 240-245. 